\title{
Flexural and interlaminar shear study of hybrid woven kenaf/recycled GFRP (rGFRP) composites subjected to bending load
}

\author{
Siti Khalijah Jamal 1,*, Shukur Abu Hassan ${ }^{1,2}$, Wong King Jye ${ }^{1,2}$, Mohd Yazid Yahya 1,2 \\ ${ }^{1}$ Faculty of Mechanical Engineering, Universiti Teknologi Malaysia, Johor, Malaysia \\ ${ }^{2}$ Centre for Composites, Universiti Teknologi Malaysia (UTM), Johor, Malaysia
}

\section{A R T I C L E IN F O}

\section{Article history:}

Received 5 November 2016

Received in revised form

17 January 2017

Accepted 17 January 2017

\section{Keywords:}

Hybrid composites

Woven kenaf fiber

Interlaminar shear strength

Flexural

Recycled GFRP (rGFRP)

\begin{abstract}
A B S T R A C T
Delamination known as the failure at the interface between different layers is one of critical failure mechanism for laminates composites. Hybrid laminate composites comprised of unique ply material and structure, unwanted interlaminar shear stresses may occur between ply laminate due to different material behavior and properties. The aim of this research is to study structural integrity effect of interleaf glass mat and recycled GFRP waste (rGFRP) in woven kenaf reinforcement polyester composite. The properties of composites on ILSS and flexural behavior subjected to bending load were measured by flexural and short beam test (SBT). Span length to thickness ratio varies for both tests are 16:1 and 4:1 for flexural test and SBT respectively. Compression molding method was selected for composite fabrication; the fiber weight percentage ratios are constant at $35 \%$ of all samples. Results revealed that the flexural stress and flexural shear measured by flexural test is comparable for kenaf and kenaf/glass composites however, kenaf/rGFRP shows significant improvement, increased in maximum flexural stress up to $47.5 \%$. Interlaminar Shear Strength (ILSS) calculated from SBT shows comparable value for all samples with slightly increased about $10 \%$ for both hybrid composites. Failure analysis observed by Scanning Electron Microscopic (SEM) and Optical Microscope shows severe interlaminar shear failure occur on glass mat hybrid composites for both tests. From the results, it can be conclude that hybridization of glass mat and rGFRP particulate improved flexural and ILSS properties. It also can be concluded rGFRP is potential to replace glass fiber as reinforcement.
\end{abstract}

(C) 2017 The Authors. Published by IASE. This is an open access article under the CC BY-NC-ND license (http://creativecommons.org/licenses/by-nc-nd/4.0/).

\section{Introduction}

Polymer composites application has been challenged with producing fuel efficient, environmentally friendly, competitive and cost effective. New materials that deliver strength and stiffness characteristics as well as other properties are being considered, which offered by natural fibers (Fulton, 2011). The various advantages of natural fibers over man-made glass and carbon fibers are low cost, considerable low density, comparable specific tensile properties, less health risk, renewability, recyclability and biodegradability (Luthra et al., 2015). However, drawbacks for

\footnotetext{
* Corresponding Author.

Email Address: khalijahjamal@yahoo.com (S. K. Jamal)

https://doi.org/10.21833/ijaas.2017.03.008

2313-626X/C 2017 The Authors. Published by IASE

This is an open access article under the CC BY-NC-ND license

(http://creativecommons.org/licenses/by-nc-nd/4.0/)
}

natural fiber reinforced polymer, its low mechanical properties compared than glass fibers. Hybridization with glass fiber reported potentially solve this issue (Yahaya et al., 2015). The hybridization can be employed to achieve a controlled and more gradual failure in brittle fiber-reinforced composites termed as pseudo-ductility (Faruk et al., 2012).

However, hybrid composites subjected to residual stress due to its different in fiber coefficient of thermal expansion and resin wetting properties may initiate interfacial stress thus may reduce it Interlaminar Shear Strength (ILSS) properties. Unwanted interlaminar shear stresses occur between composite laminate during loading especially if the layers are comprised of different material layer (Cui et al., 2013). ILSS properties is critical in laminate composites (Sideridis and Papadopoulos, 2004). Different composite systems mix of different types of fibers and matrix, can exhibit different tensile, compressive, flexure, fatigue and fracture behaviors due to varying interlaminar 
properties. The addition of hybrid reinforcements and fillers to polymers is a fast and inexpensive method to modify the properties of composites. The effect of fillers, reinforcements and modification of reinforcements on the properties of the composite depends on their concentration, ratio, reinforcement content, and ingredients as well as on the interaction with the matrix (Venkata et al., 2009).

Number of tests have been developed to evaluate ILSS where short beam test (SBT) method involves loading a beam under three-point bending with certain dimensions, so that interlaminar shear failure is induced, SBT is the most popular due to its simplicity (Makeev et al., 2014). It is primarily used to evaluate strength of the composite when subjected to out-of-plane shear stress, but it has also be used to indirectly evaluate fiber matrix adhesion and the overall quality of the composite (Da Silva et al., 2012). SBT was used as tools in the study of bridging effect on composites laminate which may results in improving structural integrity or ILSS properties, there are two methods involved namely, chemical and mechanical modification methods. In chemical method studied was done by grown carbon nanotubes on carbon surface by injection chemical vapor deposition by Feng et al. (2015) shows significant improvement in ILSS properties. Meanwhile, one of mechanical method was reported by Kobayashi and Kitagawa (2016) incorporating fine particle such as alumina and silicon rubber aiming to improve the fiber matrix interface carbon fiber and vinyl ester resin. In woven fiber modification, 3D textile were invented and developed to overcome the shortcomings of the weaker interfaces of FRP layered laminates. However, the layered FRP components are still used in major applications due to their convenience of design, ease of manufacturing and cost savings (Wang et al., 2015). In this study, the hybrid effect of glass fiber and recycle GFRP (rGFRP) interleaf of woven kenaf laminate are investigated on its ILSS and flexural properties on bending load experiments.

\subsection{Review of existing theory-classical beam theory}

According to classical beam theories, the specimen subjected to three-point-bending load experiences tension-compression stress and shear force within the beam.

Fig. 1 shows an arrangement of flexural test and short beam test at small h/t ratios, an orthotropic beam of low shear strength is expected to fail by shear at the neutral axis.

At progressively larger $\mathrm{h} / \mathrm{t}$ ratios, the mode of failure becomes flexural. In this situation, the outer fibers fail in tension if, as is usual, the tensile strength is less than the compressive strength (Sideridis and Papadopoulos, 2004).

In this study selection of $\mathrm{h}$ for flexural test was prepared by ASTM (2010) Standard D7264/D7264M-07 and short beam test by ASTM
(2011) D2344/D2344M-13 with the h/t ratio $16: 1$ and 4:1 respectively.

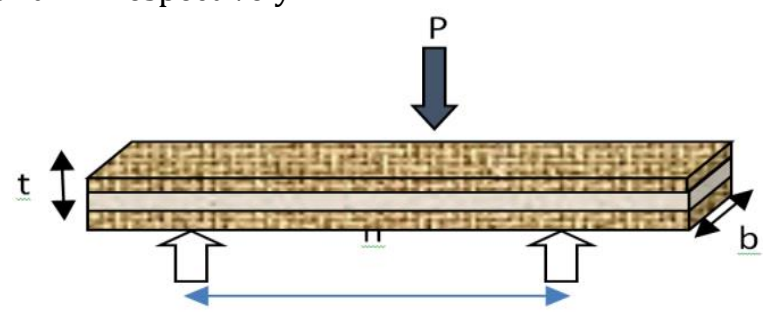

\section{Woven Kenaf}

\section{Glass/rGFRP}

Fig. 1: Three point bending test diagram $\mathrm{P}=$ Maximum peak load, $\mathrm{h}=$ Specimen length, $\mathrm{b}=$ Specimen width and $t=$ Specimen thickness

Fig. 2 is the common failure fracture during bending load, reported by others researcher and ASTM standard. The apparent of flexural stress and ILSS are given by the following equations. Flexural stress calculated as:

$\sigma=\frac{3 \mathrm{PL}}{2 \mathrm{bt}^{2}}$

Interlaminar shear stress at maximum load calculated as:

$\tau=\frac{3 \mathrm{P}}{4 \mathrm{bt}}$

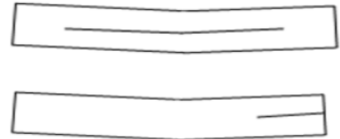

(a)

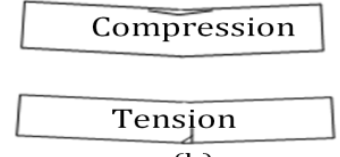

(b)
Fig. 2: Typical failure mode in the short beam test (a) Interlaminar shear (b) Flexure (Wang et al., 2015)

\section{Materials and experimental set up}

The following section describes the properties of all materials used in this research. Fig. 3 shows three main fibers involved in this research, woven kenaf, recycle glass fiber (rGFRP) and E-glass fiber.

- The woven kenaf fabric was produced by handloom weaving process using kenaf yarns. Kenaf yarn was supplied by Innovative Pultrusion Sdn. Bhd, Seremban, Malaysia. The properties of kenaf yarn measured size at 1000 tex and the density is 1.27 $\mathrm{g} / \mathrm{m}^{3}$ and woven fabrics areal density is define as $1500 \mathrm{~g} / \mathrm{m}^{2}$.

- Glass fiber mat (E-glass), supplied by SandN Chemical Sdn. Bhd, Johor Bahru. Malaysia. From the data sheet provided by manufacture, the glass fiber diameter is 12.5 ? $\mathrm{m}$, with $1.57 \mathrm{~g} / \mathrm{m}^{3}$ density using $7 \%$ styrene binder the areal density defined as 30 $\mathrm{g} / \mathrm{m}^{2}$. Average length of glass mat measured as $5 \mathrm{~mm}$ length; refer Fig. 3(c).

- Recycle GFRP waste (rGFRP) mechanical grinded supplied by Astotech Sdn. Bhd. Kuala Terengganu, 
Malaysia. Density of rGFRP measured at $1.35 \mathrm{~g} / \mathrm{m}^{3}$ and the average fiber length measured between $2 \mathrm{~mm}$ and $5 \mathrm{~mm}$. rGFRP received was wash, dried and sieve into specific size as shown in Fig. 3(b). The resin used in this study was unsaturated polyester wax resin supplied by SandN Chemicals $\mathrm{Sdn}$. Bhd. The density of polyester resin is 1.3 $\mathrm{g} / \mathrm{cm}^{3}$.

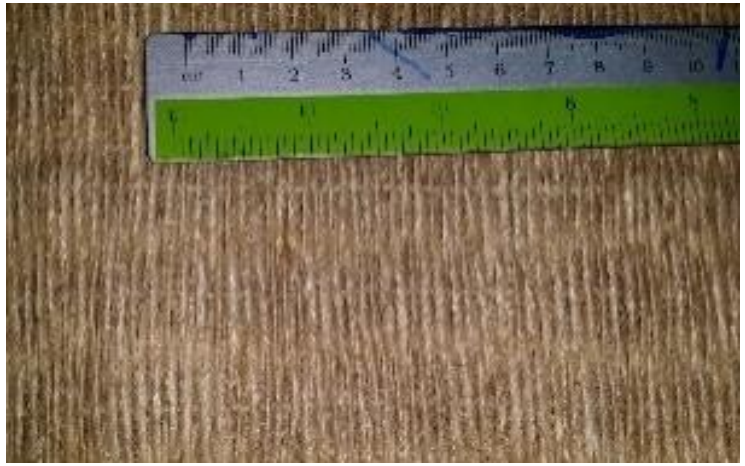

(a)

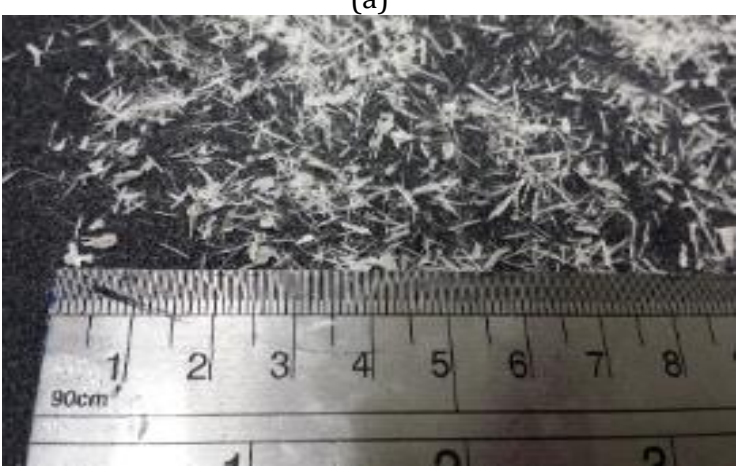

(b)

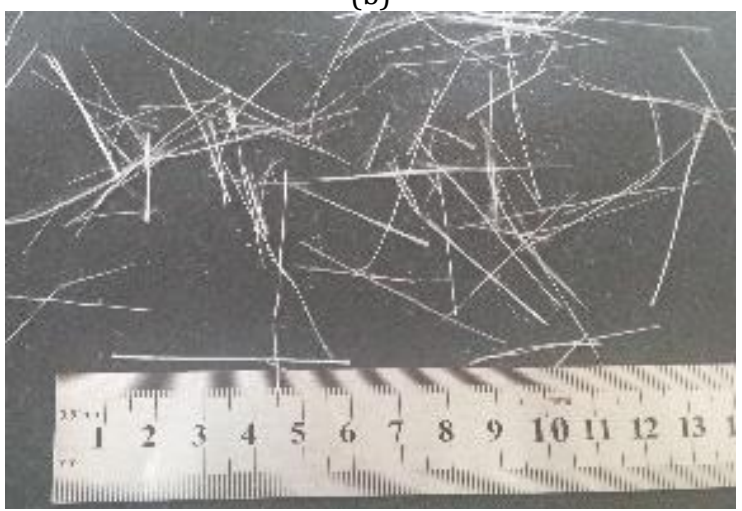

(c)

Fig. 3: Fiber reinforced (a) Woven kenaf (b) Glass mat (c) rGFRP fiber

\subsection{Preparation of composite samples}

Composites were design by closed cold compression method, cure at room temperature for 24 hours with interlayer of glass mat and rGFRP particulate between two layer of woven kenaf sheets. Polyester resin used as the binder and Methyl ethyl ketone peroxide (MEKP) hardener with $1 \%$ weight percentage by the resin were mix prior of fabrication process. Three types of composites sample fabricated, 2 layer kenaf name as (KL00), kenaf/glass mat composites with glass fiber interleaf name as
(KLCSM) and kenaf/rGFRP weight as same areal weight density as glass mat as (KLF100).

The fabrication process start with the polyester resin poured and spread over fiber before compressing in the closed mold by hydraulic compressor at one bar pressure. The average composite fiber-resin fraction is constant at average $37 \%$ weight percentage and average thickness measured at $4 \mathrm{~mm}$. The composite plate was cut using band saw into samples size of according to span length $16: 1$ and 4:1 span length to thickness ratio sample flexural cut minimal $80 \mathrm{~mm}$ and short beam test sample minimal length is $20 \mathrm{~mm}$ including $20 \%$ free edge.

\section{Experimental procedure-flexural and short beam testing}

Three-point flexural test was performed at span to depth ratio of $16: 1$ as recommended by ASTM D 7264. Specimens were tested at a crosshead speed of $1.5 \mathrm{~mm} / \mathrm{min}$ using universal testing Instron5980. The short beam test was performed at span to depth ratio of $4: 1$ and specimen width $2: 1$ as recommended by ASTM D 2344. The loading rate of the crosshead speed set at $1.0 \mathrm{~mm} / \mathrm{min}$ using universal testing Instron5980. Five replicates were repeated for both tests. Fig. 4 shows testing sample for both test.

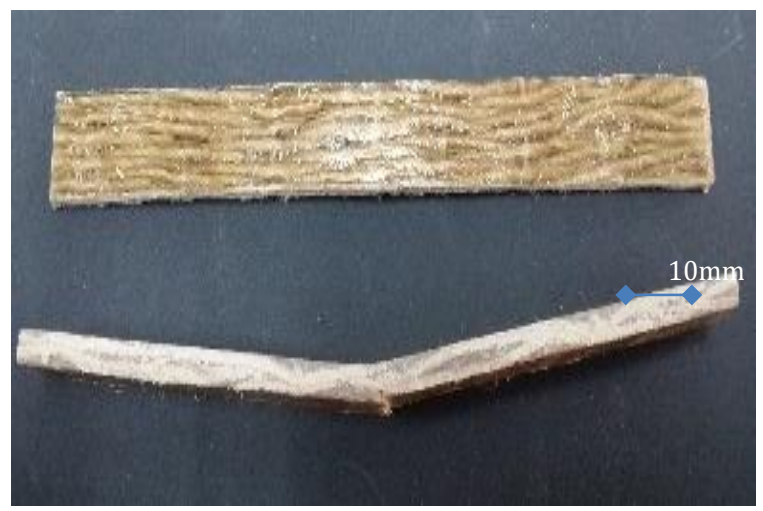

(a)

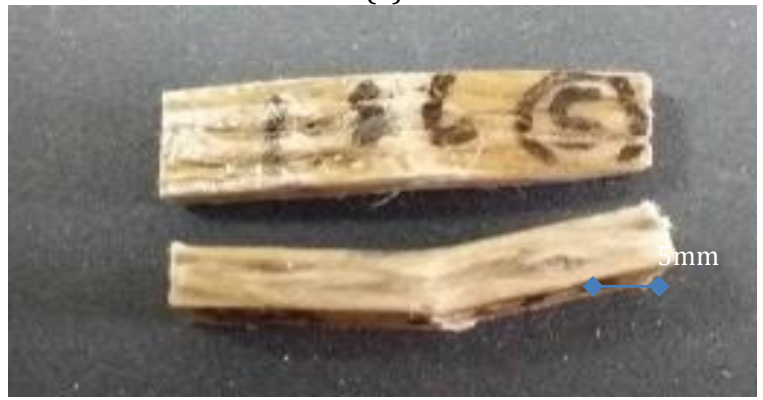

(b)

Fig. 4: Composite sample (a) Flexural (b) Short beam test

\section{Results and discussion}

\subsection{Failure modes}

According to the theory, the behavior of the test specimen in the three-point bending changes noticeably reflecting the effect of specimen aspect ratio. The domination of true bending or shear 
conditions depends upon span length to thickness ratio. Therefore, led to a difference in the failure mode of the specimens (Gupta et al., 2010). The tensile fracture failure, interlaminar failure with

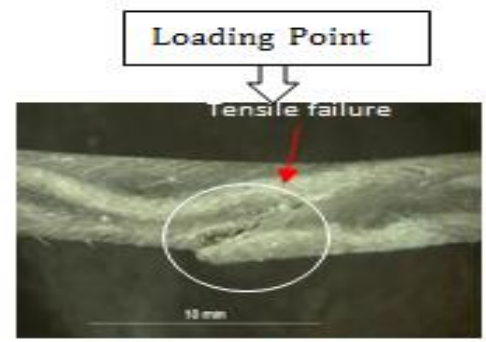

(a) Flexural fracture KLOO composite

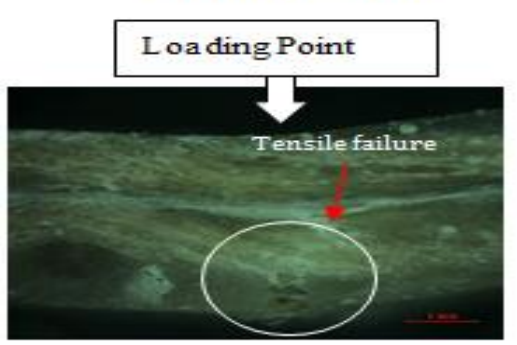

(d) ILSS fracture KLOO composite

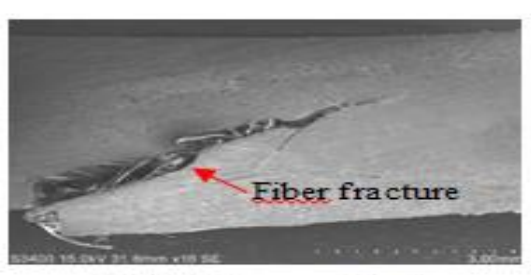

(f) SEM flexure fracture KLOO composite

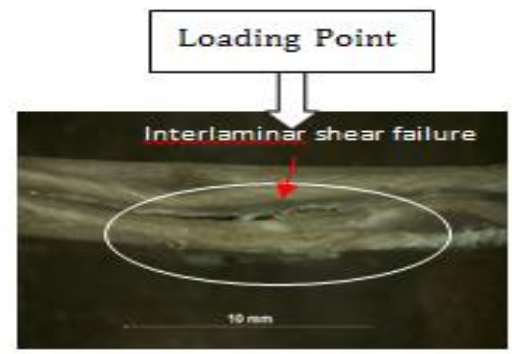

(b) Flexural fracture KLCSM composite

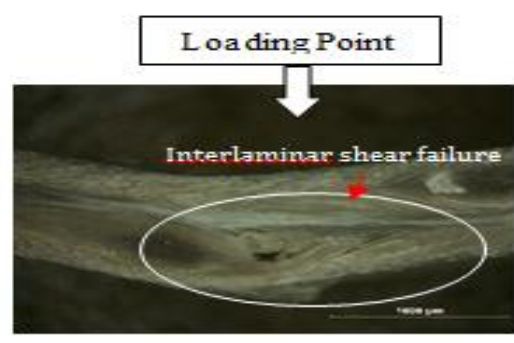

(e) ILSS fracture KLCSM composite

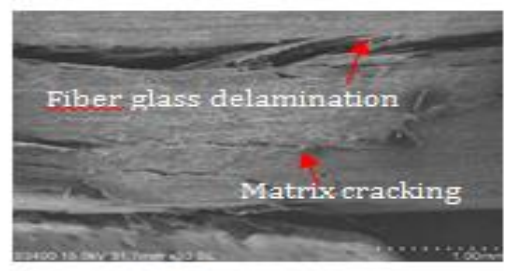

(g) SEM flexure fracture KLCSM composite

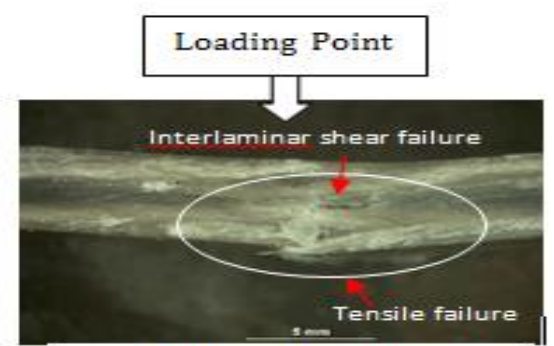

(c) Flexural fracture KLF100 combosite

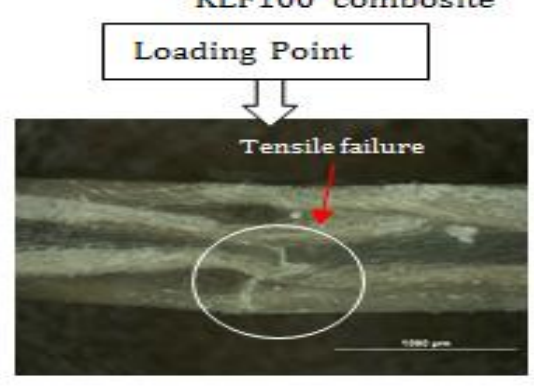

(e) ILSS fracture KF100 composite

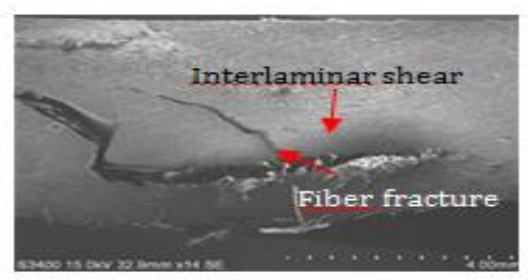

(h) SEM flexure fracture KLF100 composite

Fig. 5: Failure mode flexural test and short beam test

Optical Microscope Ziess S2000 and variable pressure scanning electron microscope (SEM)Hitachi S3400 was used to observe the failure mode fracture after test, all specimens were sputter coated with gold prior to examination for SEM. Refer to Fig. 5(a) and (d) KL00 sample shows similar failure mode on SBT and flexural test identified as tensile failure according to failure theory as shown in Fig. 2. Meanwhile, combination of interlaminar shear and tensile failure observed on KLCSM sample as accordingly (Fig. 5(b) and 5(e)). KLF100 samples shows failure effect of interlaminar shear and tensile failure on flexural test but in short beam test only tensile failure observed. Fig. 5(f-h) show the SEM of flexural fracture severe damage on matrix cracking and fiber delamination observed on KLCSM samples.

It can be concluded that rGFRP reinforcement (KLF100) help improved ILSS of composites and reduce interlaminar shear failure. The experimental data tabulated in Table 1 . In general woven kenaf interleaf rGFRP achieved higher in flexural properties compared to KLCSM and KL00. Hybrid glass with kenaf shows comparable value on flexural properties agreed as review by Saba et al. (2015). Flexural stress of KLF100 increased by $47.3 \%$ compared to KL00 and flexural shear increased from $3.99 \mathrm{MPa}$ to $8.69 \mathrm{MPa}$ accordingly. The effect of
rGFRP hybrid to the flexural deflection is comparable. The ILSS of kenaf composites is increased by hybrid with glass and rGFRP. ILSS valued increased by $12.5 \%$ and $10.5 \%$ for KLCSM and KLF100 respectively.

Hybrid effect on kenaf composites shown in graph load versus displacement curve (Fig. 6), the effect of span length (L) over thickness (h) is observed. Fig. 6(a) shows slightly nonlinear trend and sudden dropped failure when peak load is attained signifies a brittle behavior of all composite samples. Comparable curvature observed for KL00 and KLCSM sample, meanwhile KLF100 shows higher flexural stress. KL00 shows higher in flexural displacement spectacles its high in flexural elasticity compared with other samples. Hence, hybridization of rGFRP into woven kenaf composites results in increase material stiffness.

In Fig. 6(b), curve load-displacement graph for smaller $\mathrm{L} / \mathrm{h}$ ratio design for short beam test $(4: 1)$. All curve shows different behavior after reach failure peak. KLCSM samples show the higher peak load with sudden drop just after peak load reached. This behavior indicates a brittle material behavior with sudden failure. KL00 samples show the curve progressively reach peak height with higher displacement compared to the KLF100 samples. 
Progressive failure expected for this sample due to softening effect of failure.

However, for KLF100 two peak observed on the curvature this is because of micro cracking of resin propagate observed as shown in Fig. 5(e). Reinforcing of the rGFRP not only increased ILSS, but reduces the sudden failure of composites. This finding agreed with studied done by Fan et al. (2008) on enhancement of glass fiber reinforced multi-wall carbon nanotubes and Da Silva et al. (2012) studied on hybrid curaua/glass and sisal/glass composites.

Table 1: Felxural shear and interlaminar shear properties of the composites

\begin{tabular}{ccccccc}
\hline Sample & $\begin{array}{c}\text { Flexural } \\
\text { Stress, } \sigma \\
(\mathrm{MPa})\end{array}$ & $\begin{array}{c}\text { Flexural Shear, } \\
\tau\end{array}$ & $\begin{array}{c}\text { Deflection at } \\
\text { Max. Load } \\
(\mathrm{MPa})\end{array}$ & $\begin{array}{c}\text { Short Beam } \\
\text { Stress } \\
(\mathrm{MPa})\end{array}$ & $\begin{array}{c}\text { Short Beam } \\
\text { Shear/ILSS } \\
(\mathrm{MPa})\end{array}$ & $\begin{array}{c}\text { Deflection at } \\
\text { Max. Load } \\
(\mathrm{mm})\end{array}$ \\
\hline KL00 & 123.39 & 3.99 & 4.28 & 161.30 & 16.95 & 0.80 \\
KLCSM & 124.07 & 4.33 & 3.69 & 153.59 & 19.08 \\
KLF100 & 181.98 & 8.69 & 4.50 & 145.22 & 18.70 \\
\hline
\end{tabular}

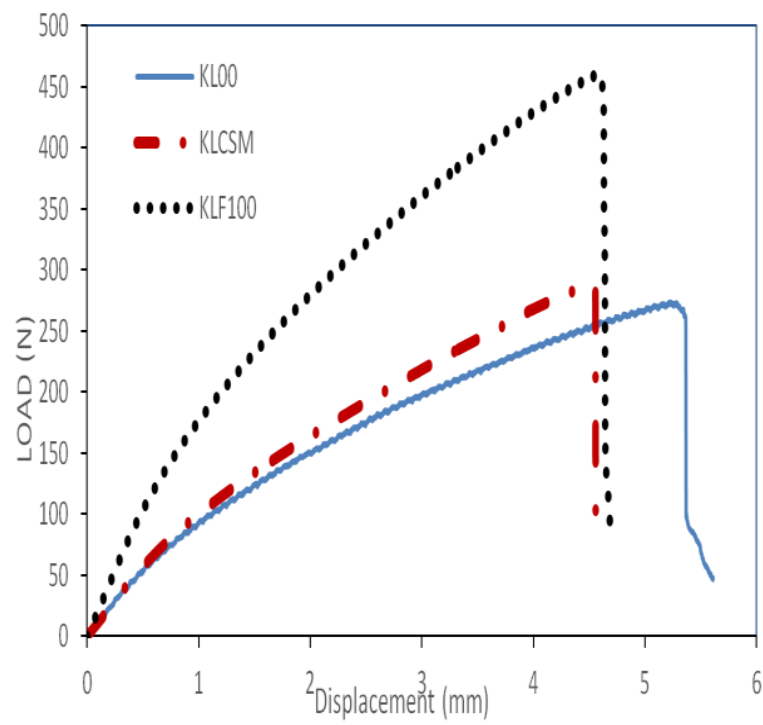

(a)

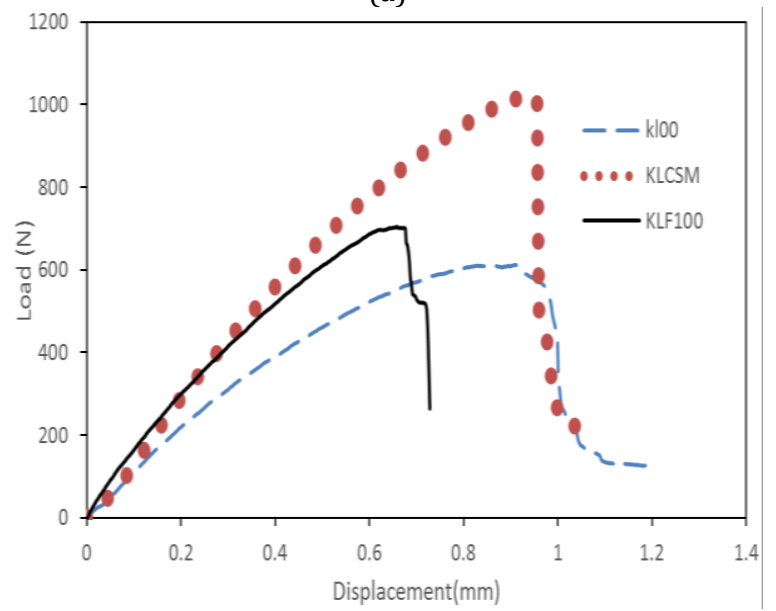

(b)

Fig. 6: The load-deflection curves of three different sample kenaf and hybrid kenaf composites (a) Flexural test (b) Short beam test

\subsection{Interlaminar shear properties}

The ILSS versus short beam strain curves of woven kenaf/polyester and hybrid woven kenaf/glass and woven kenaf/rGFRP evaluated using short beam test plotted as Fig. 7. In general, all curves shows are comparable. KLCSM curves shows higher ILS strength followed by KL00, kenaf composites shows the lowers ILSS value. The after peak load behavior observed agreed with load versus deflection curves (Fig. 6(b)). The standard deviation maintained below 20\% after 5 replication represent in the bar graph. This finding agreed with studied done by Zhang et al. (2013) on hybrid unidirectional flax glass fiber, hybrid flax increase in ILSS value by nearly $30 \%$ compared to flax phenolic composite.

\section{Conclusion}

The bending properties and behavior of woven kenaf composites using glass mat and rGFRP as interleaf reinforcement have been successfully studied and their performance was compared to control sample kenaf composites (Fig. 8).

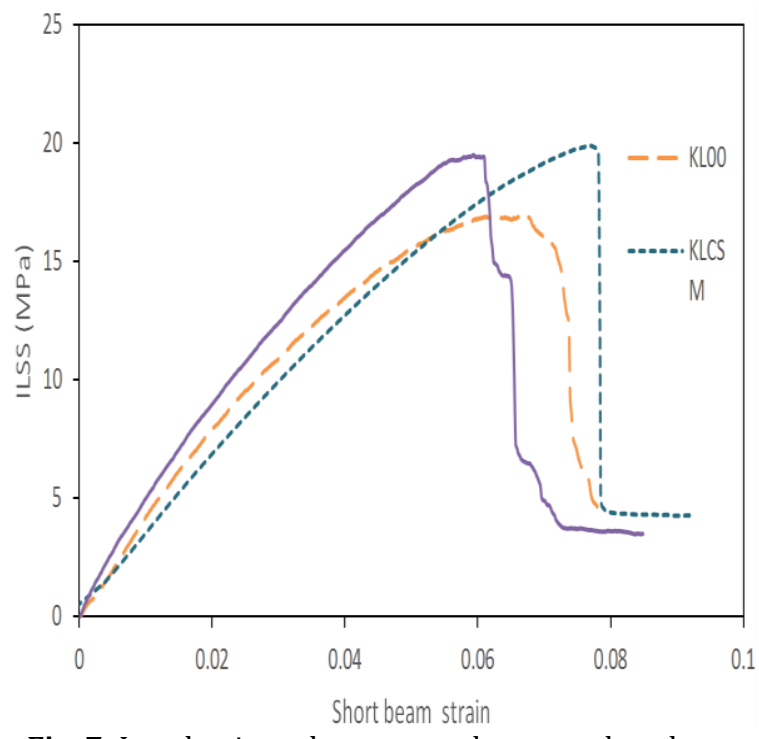

Fig. 7: Interlaminar shear strength versus short beam strain curve of composites

- The hybridization of rGFRP proved to increased composites flexural and ILSS properties. Flexural stress significantly improved with $47.3 \%$, with reduced ILSS failure mode its shows performed better than virgin glass fiber mat.

- The failure fracture from flexural test revealed that increased in flexural strength of KLF100 composites is because rGFRP increased interlaminar bonding.

- ILSS curvature signifies different behavior effect of rGFRP hybrid, increased by $10.5 \%$ in ILSS value rGFRP found to perform tolerate properties with 
higher ILSS value compare to kenaf composites at the same time performed gradual failure.

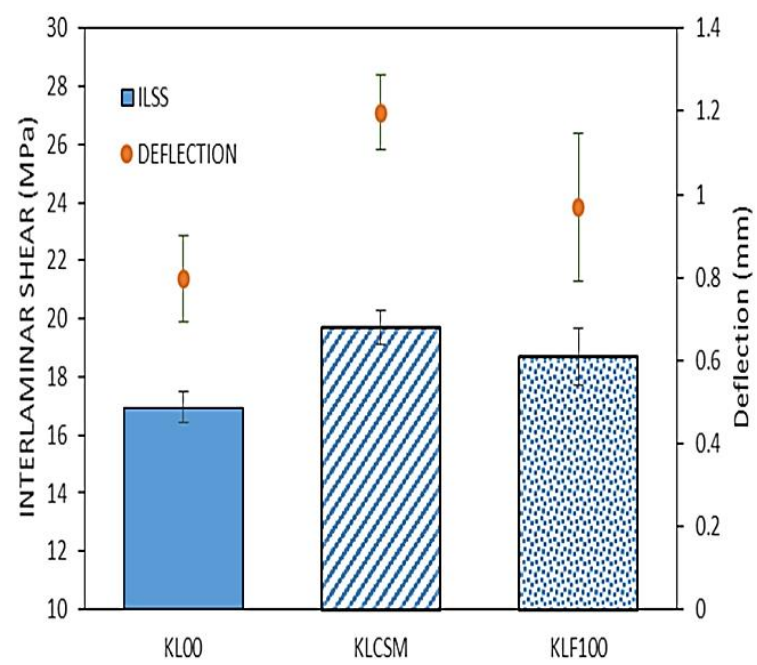

Fig. 8: Interlaminar shear strength versus short beam strain curve of composites

\section{Acknowledgment}

The authors would like to thank Universiti Teknologi Malaysia for funding this research and UTM Research Management Centre (RMC) for managing the research activities under Vot 10H22.

\section{References}

ASTM (2010). ASTM Standard D7264/D7264M-07: Standard test method for flexural properties of polymer matrix composite materials. Annual Book of ASTM Standards, Pennsylvania, USA.

ASTM (2011). ASTM D2344/D2344M-13: Standard test method for short-beam strength of polymer matrix composite materials. Annual Book of ASTM Standards, Pennsylvania, USA.

ASTM (2011). D2344/D2344M-00: Standard test method for short-beam strength of polymer matrix composite materials and their laminates. Available online at: http://file.yizimg.com/ 175706/2012021310023387.pdf

Cui H, Koussios S, Li Y, and Beukers A (2013). Measurement of adhesive shear properties by short beam shear test based on higher order beam theory. International Journal of Adhesion and Adhesives, 40: 19-30.

Da Silva LV, Junior JHSA, Angrizani CC, and Amico SC (2012). Short beam strength of curaua, sisal, glass and hybrid composites. Journal of Reinforced Plastics and Composites, 32(3): 197 206.
Fan Z, Santare MH, and Advani SG (2008). Interlaminar shear strength of glass fiber reinforced epoxy composites enhanced with multi-walled carbon nanotubes. Composites Part A: Applied Science and Manufacturing, 39(3): 540-554.

Faruk O, Bledzki AK, Fink HPP, and Sain M (2012). Biocomposites reinforced with natural fibers: 2000-2010. Progress in Polymer Science, 37(11): 1552-1596.

Feng L, Li K, Si Z, Song Q, Li H, Lu J, and Guo L (2015). Compressive and interlaminar shear properties of carbon/carbon composite laminates reinforced with carbon nanotube-grafted carbon fibers produced by injection chemical vapor deposition. Materials Science and Engineering: A, 626: 449457.

Fulton IT (2011). The effect of layup and pressure on mechanical properties of fiberglass and kenaf fiber composites. M.Sc. Thesis, Mississippi State University, USA.

Gupta N, Woldesenbet E, Hore K, and Sankaran S (2010). Response of syntactic foam core sandwich structured composites to three-point bending. Journal of Sandwich Structures and Materials, 4(3): 249-272.

Kobayashi S and Kitagawa J (2016). Effect of fine particle incorporation into matrix on mechanical properties of plain woven carbon fiber reinforced plastics fabricated with vacuum assisted resin transfer molding. Composites Part B: Engineering, 85: 31-40.

Luthra S, Kumar S, Garg D, and Haleem A (2015). Barriers to renewable/sustainable energy technologies adoption: Indian perspective. Renewable and Sustainable Energy Reviews, 41: 762-776.

Makeev A, Carpentier P, and Shonkwiler B (2014). Methods to measure interlaminar tensile modulus of composites. Composites Part A: Applied Science and Manufacturing, 56: 256-261.

Saba N, Paridah MT, and Jawaid M (2015). Mechanical properties of kenaf fibre reinforced polymer composite: A review. Construction and Building Materials, 76: 87-96.

Sideridis E and Papadopoulos GA (2004). Short-beam and threepoint-bending tests for the study of shear and flexural properties in unidirectional-fiber-reinforced epoxy composites. Journal of Applied Polymer Science, 93(1): 63-74.

Venkata RG, Shobha RT, Chowdoji RK, and Venkata NS (2009). Flexural, compressive, and interlaminar shear strength properties of kapok/glass composites. Journal of Reinforced Plastics and Composites, 28(14): 1665-1677.

Wang X, Zhao X, Wu Z, Zhu Z and Wang Z (2015). Interlaminar shear behavior of basalt FRP and hybrid FRP laminates. Journal of Composite Materials, 50(8): 1073-1084.

Yahaya R, Sapuan SM, Jawaid M, Leman Z and Zainudin ES (2015). Effect of layering sequence and chemical treatment on the mechanical properties of woven kenaf-aramid hybrid laminated composites. Materials and Design, 67: 173-179.

Zhang Y, Li Y, Ma H and Yu T (2013). Tensile and interfacial properties of unidirectional flax/glass fiber reinforced hybrid composites. Composites Science and Technology, 88: 172-177. 